\title{
KENKO: EL VIAJE A LA SEMILLA
}

Kenko: the trip to the sed

\author{
Edmundo Motta Zamalloa ${ }^{1}$
}

\begin{abstract}
RESUMEN
Kenko significa, según Ludovico Bertonio, "cosa tuerta que da buelta". Y según los actuales abuelos de lengua aymara es "lo torcido", semejante al "camino quebrado en zigzag", que ayuda a encontrar la verdad, la esencia del ser humano, el origen y la identidad del nombre y del hombre. Es una ruta inversa al arco de diferenciación por la que transita el ser visto por la filosofía de occidente. El tema se aborda aquí con un enfoque intercultural.
\end{abstract}

Palabras clave: Kenko, búsqueda de esencia, estructura del cosmos.

\section{ABSTRACT}

Kenko means, according to Ludovico Bertonio, "one-eyed thing that turns". And by today's grandparents of Aymara language, it is "the crooked" like "zigzag path", which helps to find the truth, the essence of the human being, the origin and the identity of name and man. It is an inverse path to the arc of differentiation by which the being, seen by Western Philosophy moves. The issue is addressed here with an intercultural approach.

Keywords: Kenko, search for essence, structure of the cosmos.

\section{INTRODUCCIÓN}

Un signo de distinción del pensamiento andino es el hecho de percibir al ser humano integrado al cosmos, mientras que en occidente ha seguido un arco de diferenciación que lo ha separado de la naturaleza hasta volverlo en un "hombre unidimensional". En occidente la persona es sinónimo de individuo -sujeto básico en el que se instaura la modernidad-, hombre-individuo o mujerindividuo. Para el andino la persona es chachawarmi, hombre y mujer juntos, complementados.
Quizá el enunciado circular "está el hombre en la naturaleza que está en la no-naturaleza que está en el hombre", define cabalmente la condición de "ser integrado" del andino, el cual acarrea consecuencias en las diversas esferas de la vida comunitaria, el imaginario y la cultura en general.

Al plantear el tema del hombre, la filosofía ha desarrollado una diversidad de conceptos relacionados con su génesis, su condición humana o la pérdida de ella, así como su permanencia y destino, tomando como punto de partida el vínculo del hombre con la naturaleza,

\footnotetext{
${ }^{1}$ Doctor en Filosofí. Docente de la Universidad Nacional Jorge Basadre Grohmann. Tacna - Perú.

Correoelectrónico:parmenidesc25@hotmail.com
} 
una relación que se ha vuelto funcional a la evolución del pensamiento que va del mito a la ciencia. Comprende desde los cosmólogos griegos, el aristotelismo que pretende definir al hombre estableciendo el argumento que los diferencia, los estoicos y naturalistas posteriores que postulan la reivindicación de la condición natural del ser humano, hasta la modernidad que construye la imagen del hombre emancipado de la naturaleza y de la común idad. Los racionalistas (con Descartes a la cabeza) devuelven a la razón y al conocimiento basado en ella la legitimidad del saber y el pensamiento. El empirismo de Bacon no fue menos, sobre todo, si se toma en cuenta lo que solía decir a propósito de cómo gobernar las fuerzas de la naturaleza. Son las ideas de Morín, para cerrar el largo señalamiento de pensadores, a finales del siglo $X X, y$ en lo que va del presente, una de las voces que recoge las ideas dispersas de subjetivistas y relativistas en la concepción del hombre, que elabora una teoría envolvente de la condición humana al postular que el hombre, desde épocas primitivas, es un ser complejo en todo sentido, y en lo que atañe a su performance mental es al mismo tiempo mítico y lógico, racional e irracional, mágico y práctico.

Tener una idea del lugar que el hombre, occidental o andino, ocupa en el cosmos, al decir de Max Scheler, reviste una doble importancia: teórica, pues saber con alguna certeza cómo se percibe a sí mismo el hombre, ayuda en el sentido práctico a entender la "otredad" a la hora de resolver (o disolver) problemas (conflictos) que no se agotan en la esfera de los intereses colectivos o individuales de orden económico. Adicionalmente se abre otra ventana para retomar la discusión acerca de la racionalidad andina.

Aquí hemos tomado en común a quechuas y aymaras, cuya matriz de origen y evolución proviene de los Andes, y basándonos en su discurso mítico y sus imágenes rituales.

\section{LA CURVATURA DEL COSMOS $Y$ LA RUTA DEL SER}

El tránsito del objeto al sujeto no parece tan sencillo si se lo formula desde la ontología o la gnoseología; supone un largo recorrido sobre todo si se trata de la condición humana.

El arco de diferenciación del hombre con respecto a los demás seres de la naturaleza y, en particular, con respecto a los animales, ha sido materia de reflexión desde los inicios de la filosofía. Se ha echado mano a diversas marcadores de distanciamiento, como ese argumento que decía solo el hombre era capaz de pensar, de reír, de imaginar, o tener un alma, o de expresarse con símbolos. Tales marcadores de distanciamiento no se reducen a discriminar al hombre del animal, van más allá y comprenden a todo ser dotado de vida, desde el más elemental en que halla su punto de arranque y continúa de una manera evolutiva hasta lograr el punto máximo de realización superior. Nicolás de Cusa llamó "la ruta del ser" y después Max Scheller lo ha presentado como "la curvatura de la estructura del cosmos". Otros filósofos la han simplificado al tránsito que realiza el hombre de su condición de objeto a la de sujeto.

El pensamiento de Nicolás de Cusa (1401-1464) ${ }^{1}$ expresa en cierta medida el ideal medieval de la totalidad, el conjunto del cosmos espiritual y del cosmos físico, sin detenerse en ninguna distinción (Cassirer, 1951, p.21). Concibe el mundo como despliegue o teofanía, y se apoya en la antigua división del universo de Juan Escoto Erígena: "La naturaleza que crea y no es creada, la que es creada y no crea, $y$, finalmente, aquella 
que no crea ni es creada" (Cassirer, o.c.p, 61). Tomando la influencia del neoplatonismo el cosmos está dispuesto en grados. Según esa doctrina el mundo se divide en pares dicotómicos de inferior y superior, de sensible e inteligible, se niegan entre sí pero en esa negación radica su esencia ${ }^{2}$.

Y como esa negación reclama, para ser superada, de la intervención de un mediador, de un puente, pues se abre entre ambos mundos, según el Cusano, un vínculo espiritual y de mediación, que permite el paso de lo infinito a lo finito y el retorno de lo finito a lo infinito (Cassirer, o.c.p, 24). Ese entre está conformado por las inteligencias puras y las fuerzas celestiales, que se dividen en tres círculos distintos, cada uno de los cuales se articula a su vez en triple órbita ${ }^{3}$.

La ruta que describe el ser, lo dirá más tarde Charles de Bouelles (14791566), en su paso del mero ser a la autoconciencia comprende cuatro momentos: Esse, vivere, sentire, intelligere ${ }^{4}$. Hegel la postularía como la conversión de la sustancia en sujeto. "La razón es aquella fuerza por la cual la madre naturaleza retorna a sí misma" (Cassirer, o.c. p. 119).

De manera similar, el conocimiento describe una ruta evolutiva a partir del que se obtiene por los sentidos (como imágenes insuficientes); por la razón («ratio», basado en la diversidad de los contrarios); y por el intelecto («intellectus»), que conduce a la verdad de Dios y es la instancia que resuelve el conflicto de los contrarios, a la que el Cusano llamó coincidencia de los opuestos («coincidentia oppositorum»).

Para poder encontrar el verdadero conocimiento, o esencia, de las cosas hay que separarse de las características de las cosas. Esa esencia, o concepto puro, es de naturaleza cualitativa que prescinde de la extensión de la experien- cia. Y el medio para hacerlo es el intelecto, con él se capta la cualidad, mientras que la experiencia capta la extensión, por asimilación y por comparación.

Las ideas del Cusano, en particular las referentes a la coincidencia de los opuestos, se anticipan a Hegel quien le dará un sentido dialéctico. Mientras que en el Cusano la coincidencia de los opuestos es superada por el espíritu que en último caso es Dios, en Hegel será por vía de síntesis, y el espíritu es una idea afectada por la potencialidad de exteriorizarse. En ambos pensadores, el arco de diferenciación va del mundo de lo sensible al espíritu capaz de volverse sobre sí mismo.

El arco de diferenciación que describe el ser es denominado por Scheler ${ }^{5}$, "la curvatura de la estructura cósmica". El ser vital, como ente psicofísico, traza un recorrido desde la condición de materia inorgánica hasta alcanzar el punto superior definido por el espíritu ${ }^{6}$. Los estadios que recorre el ser vital son, progresivamente: Impulso afectivo, instinto, memoria asociativa, inteligencia práctica, espíritu.

El impulso afectivo es el primer grado de la cadena que recorre el ser vital, corresponde al nivel vegetativo, en el que el impulso vital está ya adaptado a su medio con arreglo a las direcciones finales del "arriba" y el "abajo" (hacia la luz y hacia la tierra). Carece de desplazamiento, y allí la planta "se prepara el alimento que necesita con materias inorgánicas" (Scheler, 1964, p.31). Scheler sostiene que la planta carece de las funciones de notificación (que está presente en los animales), que determina el trato con otros animales y emancipan al animal de la presencia inmediata de las cosas. Nuestro autor piensa que sólo el hombre se alza por encima de las funciones de expresión y notificación con la función de representación y denomina- 
ción de signos (Scheler, o.c. p, 32).

El segundo estadio del recorrido del ser vital es el instinto, que posee los atributos de transmitir la relación de sentido y ritmo, y responde a situaciones importantes para la vida de la especie y no para la experiencia particular del individuo (Scheler, o.c.p, 36).

El tercer estadio corresponde a la memoria asociativa, el cual brota de la vida instintiva. Se adquiere por la reiteración de estímulos y por la eventualidad del principio de éxito y error. Sólo el hombre es capaz de un recuerdo consciente y libre de lo pretérito, y de un creciente descoyuntamiento de la tradición (Scheler, o.c. p, 46).

El cuarto estadio está marcado por la inteligencia práctica. Scheler afirma que la conducta inteligente posee sentido, no se deriva de ensayos previos, responde a situaciones nuevas y suele acontecer de súbito. Su sentido último es siempre la acción ${ }^{7}$. El resultado es un tipo de conocimiento práctico, previo a uno teórico que Scheler piensa es producto del "acto de ideación", completamente distinto y que se adquiere por anulación ficticia de la realidad (por reducción fenomenológica, llamaría Husserl).

$\mathrm{La}$ "ideación" ${ }^{8}$ es un acto propiamente espiritual, pues desrealiza lo concreto para alcanzar la idea, la esencia, el concepto. A continuación Scheler se propone señalar en el espíritu la diferencia esencial entre el animal y el hombre, definiendo como su propiedad fundamental "la independencia, libertad o autonomía frente a los lazos y la presión de lo orgánico, de la vida, de todo lo que pertenece a la vida y por ende también de la inteligencia impulsiva" (Scheler, o.c. p, 58). Este ser espiritual ya no está vinculado a sus impulsos, ni al mundo circundante, sino que es libre y abierto al mundo.

Heidegger dirá que el Espíritu es el modo de ser del ser ahí, capaz de elevarse sobre el propio hombre, o trascenderse (a lo Kant), es el punto culminante del ser vital, en el que se percibe como un ser para sí (Sartre).

Resumiendo: En este punto reside toda la importancia e interés de la propuesta de Scheler; tomando como base el recorrido del ser vital, ha sugerido la "curvatura de la estructura del cosmos": partiendo de lo inorgánico y el impulso extático (hacia fuera) el ser vital debe alcanzar estadios superiores para volverse hacia sí mismo (hacia adentro).

Aunque Max Scheler sólo menciona como inorgánico el estadio previo al del impulso afectivo, debemos resaltar la enorme importancia que éste tiene en el surgimiento de las cosmovisiones del mundo. Son inorgánicos aquellos elementos componentes de la complejización de la materia presentes ya en las culturas más antiguas, como la India, China, Egipcia, Azteca, Andina. Los filósofos presocráticos (Tales, Anaxímenes, Empédocles, etc.) hallaban en el agua, la tierra, el aire, o el fuego, el elemento primordial capaz de contener la explicación del mundo, de los seres vivos en general y del hombre. De alguna manera estos pensadores señalaban ya el principio de la curvatura del cosmos.

Estas ideas vienen muy a propósito del pensamiento andino referente a la percepción que posee el hombre que desarrolló una cultura, definido en gran parte por su relación con el cosmos. Para adelantar en una frase, el hombre andino tiene plena conciencia de su condición de ser cósmico. La tarea que vendrá luego será mostrar, recurriendo a diversas fuentes -documentales y de origen empírico-este vínculo. 


\section{El ascetismo del intelecto y la empatía del espíritu}

Al trazar el esquema de la filosofía y el propósito que le corresponde como una función de la mente humana, el filósofo británico Bertrand Russell ${ }^{9}$ dedica su atención en primer término a la sensibilidad (del hombre) con respecto al medio que constituye la condición indispensable para el conocimiento del mismo. Luego de considerar el mundo sensible como espacio físico (a diferencia del espacio perceptivo), el autor vuelve a ocuparse del hombre "tal y como se aparece a sí mismo y no solamente como es conocido por el observador externo" (Russell, 1974, p. 622). En este punto destaca la acción de los fenómenos mnémicos en el comportamiento de los seres humanos debido a los efectos producidos por los hechos del pasado. Finalmente, Russell aborda el fin de la filosofía. Dice: "La filosofía es lo que más aproxima a los seres humanos a aquella contemplación del Universo en conjunto, amplia e imparcial, que nos eleva por el momento sobre nuestro destino puramente personal", (Russell, o.c. p, 631). Obedece a un cierto ascetismo del intelecto que es bueno como parte de la vida, si bien no puede ser constituida totalmente en tanto que permanezcamos como animales empeñados en la lucha por la existencia. Cuando filosofamos obtenemos algo de gozo parecido al que experimenta el místico que se pone en armonía con la "voluntad divina". Este gozo no se deriva del hecho que la filosofía busque explicaciones, sino de la búsqueda en sí. Por eso sostiene Russell "la actitud en la que el hombre (moderno) debiera enfrentarse al Universo es en la de un completo respeto de sí mismo" (Russell, o.c.p, 633). El papel de la filosofía es o debería ser "mostrarnos los fines de la vida y los elementos de la misma que tienen valor por símismos" (Russell, o.c. p, 634).
Las ideas subrayadas pueden tomarse como puntos de reflexión del pensamiento andino. En cuanto a la sensibilidad con respecto al medio, es vital para señalar la sintonía plena que guarda el andino con la naturaleza del entorno y el universo entero. El andino se percibe como parte del medio y no externo y menos extraño a él. En lo que respecta a la causación mnémica, el pasado condiciona el presente o tiene consecuencias en el comportamiento actual del andino, no en el sentido de la historia -del devenir-, sino de dependencia respecto de los ancestros y de los hechos primordiales al punto de concebir el tiempo futuro en una dimensión del pasado.

Quizá lo que la filosofía no pudo en el hombre de los Andes desarrollar la actitud contemplativa, lo consiguió la empatía de espíritu y el paisaje, fijando en los sentidos la diversidad de colores y claroscuros, contrastando altitudes y profundidades, mezclando voces y sonidos, descubriendo en el límite de las cosas un halo mágico. Procuró a su modo infundirle una espiritualidad parecida al "ascetismo del intelecto" que lleva al andino, como en el caso de los abuelos, a buscar la esencia de su identidad cósmica.

El filósofo francés Jean Paul Sartre postula en términos de tránsito del ser de la condición de objeto a la de sujeto, como una solución de continuidad del ser-en-si al ser-para-sí. Mientras que el ser-en-sí corresponde al ser de las cosas, de los objetos, del hombre mismo considerado como res extensa, el cuerpo que existe y muere; el ser-para-sí se relaciona con el ser consciente, pensante, el cogito dotado de libertad. Todavía hay otro estadio que define al ser en su dimensión social que se postula como el ser-paraotro, que se da en interacción con sus semejantes y mediado por el conflicto. 
Ahora bien, ¿cuál es la ruta que sigue el ser en la cultura andina? ¿Hay un comienzo en la condición de objeto, o naturaleza, y un final en la condición de sujeto emancipado de la naturaleza? El pensamiento andino es más cercano a la concepción vitalista que hace de la vida una categoría básica de la concepción total del hombre y del espíritu enfatizando el alcance del principio de la vida ${ }^{10}$. Ese principio vital y espíritu-raíz en la cultura andina es conocido con el nombre de kamaqen, el centro de la cosmovisión vitalista andina; forman parte de esa visión el culto a los elementos concebidos en su doble naturaleza material y espiritual, ligados en el contexto ritual con los eventos astronómicos, los solsticios y los equinoccios, actos voluntarios que son liderados por los abuelos.

\section{UN ABUELO PLURAL}

Los diccionarios aymaras consignan el vocablo "achachila" con el significado de "abuelo", que en términos generales se refiere al antepasado o ancestro. Pero también es común atribuir el término "achachila" a la montaña tutelar de la comunidad, significado que asociado a su sentido general viene a estipular que la montaña adquiere la categoría de ancestro. Quizá el paulatino desplazamiento del aymara ha hecho que el uso de la palabra "abuelo" sea más frecuente, inclusive en círculos estrictamente rituales. Y no solo para referirse en los dos sentidos que hemos señalado líneas atrás, sino aludiendo a otros significados que acabaron por convertir en un término polisémico. Así, "abuelo" es el padre del padre, la montaña, el maestro del ritual, el sabio amauta, y cada uno de los elementos esenciales en que se funda la naturaleza.

\section{El abuelo ancestro}

El abuelo como padre del padre es un personaje de gran trascendencia en las comunidades andinas, pues representa el tronco del cual descienden varias generaciones. No solo generaliza al ancestro, al antepasado común, sino que, a medida que se aleja del ego, adquiere la cualidad de venerable y sagrado. Todavía en vida el anciano, abuelo, es depositario de la sabiduría adquirida por la experiencia, su palabra es autoridad indiscutida, sus expresiones son referencia necesaria, sus consejos son reglas para la vida. A su muerte el abuelo es asimilado en el panteón sagrado de los divinos achachilas, debiendo pasar de la condición humana a la de espíritu protector de la comunidad.

\section{El abuelo montaña}

En el imaginario aymara, "abuelo" representa también el espíritu protector que mora en la montaña y es al mismo tiempo la montaña. Es el abuelo dios, y continente del Alax Pacha o Hanan Pacha, protector de la tierra y de los hombres y animales que la habitan, el que destina agua y con él fecunda a la Pachamama. La antropomorfización de la montaña hace que adquiera el carácter de macho y tenga al costado a su mujer, "awicha" ("abuela"). Un proceso de metamorfosis ha llevado al abuelo humano a convertirse en abuelo montaña. Al morir los humanos eran llevados a las inmediaciones de la montaña. De ese hecho surgió una larga tradición, las montañas son la morada de los muertos, en particular las montañas ubicadas hacia occidente, pues la trayectoria del sol -de oriente a occidente- marcaba la ruta de los muertos. Se había configurado la montaña como el lugar que habitan los espíritus. El siguiente paso de la metamorfosis fue la identidad del espíritu abuelo con la montaña misma, dando 
lugar al abuelo montaña.

\section{El abuelo amauta}

El trato personal que se dan los integrantes de la comunidad es llamándose entre sí hermanos y hermanas sin distinción de posición económica o rango social. $Y$ extienden el mismo trato a las personas que participan con ellos aun cuando no son de su comunidad. Al maestro que conduce el ritual le llaman de la misma manera, aun cuando saben que se trata no de una persona común sino de alguien investido del saber y del poder ejecutar un ceremonial. Una persona que tiene el saber acerca de la naturaleza, de los elementos, del poder curativo de las plantas, de la oportunidad del tiempo para llevar adelante la práctica de las ofrendas, el que sabe buscar el camino que conduce a lo fasto, el que conoce la armonía de la naturaleza y el ordenamiento del cosmos y sabe cómo reconstruirlo cuando entra en riesgo y hay amenaza de caos. Este saber reconoce también niveles, en una escala que va del aprendiz al sabio, el que ha alcanzado la sabiduría y la particular visión del mundo. Los antiguos peruanos lo conocían como "amauta", y hoy le reconocen con el nombre de "abuelo". El maestro aymara Eliseo, asegura que se alcanza el estatus de abuelo después de un largo aprendizaje y de haber acumulado conocimiento y práctica. Aquí no interesa la edad, pues se puede llegar a ser abuelo a los treinta años o a los cincuenta. Lo que cuenta es el conocimiento que se demuestra en el entendimiento de las cosas y la destreza con que se conduce un ritual. En otras palabras es un iniciado que alcanza el nivel de maestro.

\section{El abuelo fuego ${ }^{11}$}

No hay acción que ponga en evidencia la necesidad del hombre de sentirse cósmico, como los ritos dedicados a los elementos de la naturaleza -tierra, agua, aire, fuego-, en el entendimiento de que tales elementos constituyen el comienzo material y espiritual del hombre y del mundo, el punto de flexión del espíritu-raíz, el principio vital, o kamaqen.

El fuego es una categoría de abuelo cuyo culto se desenvuelve en la oportunidad de un solsticio de invierno. Ha sido más difundido como el culto al sol, el Inti Raymi, el año nuevo andino. Por lo tanto, es el momento temporal más importante, marcado por la noche más larga y el frío más intenso del año.

El culto dedicado al fuego es en la práctica panandino, y Qosqo, en el pasado, tuvo la mayor trascendencia por ser el "ombligo del mundo". En la actualidad, el escenario puede ser cualquier lugar. Los "movimientos originarios" que tienen como propósito reivindicar su cultura atrayendo los rasgos más significativos de su pasado, tienen especial cuidado en elegir un escenario que sea de preferencia un sitio arqueológico, pues, en principio, allí están las huellas de los abuelos, como Miculla o Moqui.

$\mathrm{El}$ acto ritual en Miculla tiene dos momentos; la primera denominada "vigilia", se lleva a cabo en la noche (a partir de las 10 pm del día 20 de junio hasta las 6 de la mañana del día 21). Se desenvuelve alrededor de una fogata alimentada con leña, el trasfondo lóbrego y un cielo imponente como un río iluminado de estrellas, la Vía Láctea o Qoyllur Mayu. Literalmente se guarda vigilia cuando se acompaña a un enfermo (en su larga noche, el imaginario ha considerado que el sol está enfermo), o en su defecto, cuando se acompaña al recién fallecido. El solsticio del 21 de junio se ha estimado desde el tiempo de los incas como la Festividad del Sol que marca el inicio del Nuevo Año Andino (quechua y aymara, Mosoq huata y Machaq mara, respecti- 
vamente).

Durante la vigilia, en que se espera el "retorno del sol", poseedor y destinador del fuego, tras una "agonía", intervienen los "yatiris", quienes en el círculo restringido de sus integrantes se llaman "abuelos", para instruir a los hermanos allí presentes, en los mensajes de las estrellas. Dos de ellos, Eliseo y Marcelino, demostraron su profundo $\mathrm{y}$ amplio conocimiento acerca del hombre, de su cultura, de sus inquietudes, aflicciones y logros, $\mathrm{y}$, de paso, les recordaba acerca de la responsabilidad que alcanzaba a cada "hermano" y "hermana" para revitalizar la cultura de los abuelos y su sabiduría.

El abuelo Eliseo rememora la "verdadera historia" de Manco Cápac, el vencedor, y de su esposa Mama Ocllo, aportando detalles no consignados en la versión del Inca Garcilaso.

En otra historia denominada Kenko, el abuelo Eliseo sustenta generosamente toda una concepción acerca del origen de la cultura aymara y su vínculo con el cosmos. Esta identidad con el cosmos la desarrollaba también a nivel de cada persona y lo hizo tomando como referente su propio nombre. "Nuestros verdaderos nombres tienen origen cósmico y es deber de cada uno averiguarlo, debiendo retroceder para ello siete generaciones". El abuelo Eliseo resaltó la importancia de retroceder en el tiempo "para limpiar nuestros errores". Trató de demostrar persuasivamente que el hombre y el cosmos son una unidad, sustentando la idea de cómo cada individuo está hecho de fuego, de agua, de aire, de tierra. "Somos cada uno de esos elementos", sostuvo.

A su vez, Marcelino expandió sin mayor esfuerzo intelectual su visión holística, indicando la unidad de las cosas y la integridad del mundo, incluso cuando podían parecer disímiles y dis- tantes entre sí, estaban integrados. Cada cosa que ocurría en cualquier lugar del mundo nos afectaba, por eso se explicaba que durante las invocaciones rituales del día 21 en el cuadrangulario ceremonial, los invocantes ponían énfasis al pedir el bien para la humanidad, la pazy la salud.

El ritual trazado en varios esquemas, algunos sincronizados y otros en sucedáneo, con duración de cinco horas aproximadamente (desde las seis horas de la mañana), es dedicado a la salida del sol. Transcurre dentro del espacio cuadrangular, compuesto de cuatro cuadrados, uno al interior de otro, al centro del cual hay un podio reservado para la cremación de los "deseos". El cuadrangulario está conectado por una avenida, en cuyos laterales flamean wifalas tawantinsuyanas, a la mudanza (donde se realiza la danza ritual al finalizar el rito de saludo al sol). La orientación del espacio ritual está en relación a las colinas de arena, lugar por donde aparecerá el sol, que está ubicado hacia el este. Al salir, los rayos del sol atraviesan la avenida flanqueada por las wifalas, y los celebrantes los reciben en el cuadrangulario proclamando su regocijo con grandes voces y levantando ambas manos ${ }^{12}$.

Durante la vigilia, al calor y la crepitación del fuego, el abuelo Eliseo Jaliri ${ }^{13}$ cuenta la siguiente historia.

Mi nombre es Eliseo Jaliri. He rastreado siete generaciones de mi genealogía hasta que encontré mi origen. Kenko está relacionado con el tiempo, la fecha y la hora, y con el lugar donde uno ha nacido (kespej en aymara es algo degenerado).

Kenko ${ }^{14}$ es camino en zigzag. Caminando más abajo del caserío, allende la montaña, en zigzag, allí encontré mi nombre.

En el camino mi abuelo hizo 
una prueba; llevaba de la mano a un amiguito. Le puso una piedra en la mano, y a través de la piedra el amiguito percibió la conversación de sus padres. Le quitaba la piedra y el niño dejaba de escucharlos.

Nosotros tenemos los dos lados de la energía, y no de uno solo. Por eso debemos tener los apellidos de nuestros dos padres. Necesitamos tener la fuerza de los dos. Debes llevar los dos apellidos.

Rastreando su apellido encontró su origen cósmico.

Harawi es la melodía que armoniza.

Mi abuelo tenía una antara pequeña de tierra. Esa antara tenía una hermosa melodía. Él aprendió a fabricar una quena muy bonita.

Para corregir nuestros errores tenemos que retroceder siete generaciones. Para recuperar nuestra identidad y corregir nuestros errores hay que retroceder siete generaciones.

Podemos señalar algunas de las ideas del relato de Eliseo Jaliri por el interés que despierta en la medida que tales ideas se relacionan con la preocupación cósmica.

1. La búsqueda del origen cósmico (rastreando siete generaciones) que implica inmediatamente dos consecuencias: recuperar la identidad y corregir los errores.

2. Determinación de tiempo y lugar (kenko está relacionado con ambos), que proporciona singularidad a los hombres.

3. Camino en zigzag (kenko es lo oblicuo y lo torcido), que otorga sentido a la búsqueda.
4. La piedra mediadora, por intermedio de ella se puede conversar con los ancestros.

5. La fuente de energía reconoce los dos padres (masculino y femenino).

6. El canto (harawi) es principio de armonía.

\section{El abuelo tierra}

Este rito dedicado al elemento tierra se cumple en otro escenario arqueológico, de origen Inca, en el cerro Moqui ${ }^{15}$. La ceremonia de agradecimiento a la tierra se realiza la noche del 20 y el 21 de septiembre. Hay que recordar que los rituales dedicados a los cuatro elementos esenciales que constituyen la naturaleza y la vida del mundo andino en general ocurren en y durante los solsticios de junio y diciembre, y los equinoccios de septiembre y marzo. El ritual de junio es dedicado al fuego, el de septiembre a la tierra; el de diciembre al aire, y el de marzo, al agua. El ritual es un recordatorio del evento astronómico. Los solsticios marcan el inicio del frío (por eso el ritual es dedicado al fuego) y el inicio del calor (por eso el ritual al aire); los equinoccios marcan el inicio de dos estaciones de tránsito o templados; el de la primavera (tránsito del frío al calor; por eso el ritual a la tierra) y el del otoño (tránsito del calor al frío; por eso el ritual al agua).

Moqui fue seleccionado como lugar ceremonial para el ritual de agradecimiento a la tierra por varias razones: porque es un escenario abierto (siempre se recuerda que los espacios ceremoniales andinos son abiertos en oposición a los cerrados de los ritos occidentales); porque está ubicado a cierta altura (acaso valorado por su cercanía a los abuelos-montaña); porque Moqui es una construcción inca o preinca (arqueólogos norteamericanos que la visitaron en días previos afirman que son restos del 
período inca aunque sus construcciones parecen rústicas) y este es un motivo de alta significación toda vez que fue construida por nuestros ancestros y ellos "están allí, andando, esperando que escuchemos su sabiduría" (según la expresión del hermano Isaac en su alocución durante la vigilia).

El discurso ritual está formado. Una cena previa al inicio de la vigilia. El frío es acentuado por cortos y continuos vientos. El fuego arde en el cuerpo de dos troncos alrededor del cual los participantes forman un círculo. El oficiante de maestro ceremonial (hermano Saturnino) da la bienvenida y hace participar con breves alocuciones a los presentes, entre quienes se encuentran representantes de diversas instituciones. Cuando asoma sobre los cerros una línea celeste el maestro de ceremonia anuncia con el pututo el final de la vigilia. Sobreviene la ofrenda de especies a la tierra y los preparativos para recibir la llegada del sol. La alocución más importante en la vigilia fue la del hermano Isaac, cuyas palabras son una especie de discurso de orden.

Por razón de claridad y economía de espacio ordenaré sus ideas.

1. En nuestra cultura la vida es el quinto elemento. Para nosotros todo tiene vida.

2. En la cultura occidental solo hay cuatro elementos. Por eso es una cultura de autodestrucción.

3. Nuestras ceremonias se relacionan con dos solsticios y dos equinoccios.

4. Hoy al amanecer ocurrirán fenómenos especiales (vibraciones) en el universo.

5. Es una ceremonia curativa.

6. Nuestros ancestros recurrían al fuego para resolver sus problemas.

7. Las figuras rupestres no son simples dibujos. Eran centro de enseñanza del universo.
8. La figura del Suri representaba a la Cruzdel Sur.

9. La Vía Láctea es como un ser humano, se le ve caminando.

10 . He encontrado mis raíces recurriendo a nuestros abuelos.

11. Ellos [los abuelos] están andando por aquí con ojotas, buscando enseñarnos y transmitirnos sus conocimientos.

12. Cuando aprendamos como hacían nuestros abuelos volveremos a ser como era antes.

13. En el norte de Argentina hay un pueblo de nombre Pukara que ha optado vivir de acuerdo con nuestras costumbres y han pedido al gobierno de su país que les dejen vivir de acuerdo con sus costumbres, con el ayni, la reciprocidad. En este momento es el pueblo más ordenado.

14. No tenemos que ir a buscar otros modelos, todo está en nuestra cultura, en nuestras familias.

15. Por ignorancia no recurrimos a nuestros abuelos.

16. Háganle sus ceremonias, como esta que estamos haciendo, háganle en todas partes, aquí mismo.

17. jJallalla!, hermanos.

Al concluir el ritual, el hermano Saturnino comparte algo elocuente, dice sentirse renovado; su cuerpo y su espíritu se han llenado con la energía de la tierra.

\section{EL NUDO CÓSMICO Y LA BÚSQUEDA DE SENTIDO}

La idea de nudo cósmico invoca el principio de holomorfismo, de totalidad y ordenamiento. El andino "no efectúa separación alguna de una representación global en sus elementos individuales, sino que sólo está dada a la intuición una sola totalidad indivisa en la cual no 
ha tenido lugar ninguna disociación de los factores individuales, especialmente de los factores objetivos de la percepción y de los factores subjetivos del sentimiento" ${ }^{\prime 16}$. De aquí se infiere que el todo no se descompone en sus partes. Ni el aspecto objetivo de la percepción pueda desligarse de lo subjetivo. Se encuentran estrechamente vinculados y cosificados por el pensamiento, en sus propiedades y procesos, fuerzas y actividades, más aún si se plantea en el contexto de una unidad cósmica integrada por el hombre, la naturaleza y las divinidades. En consecuencia, se trata de una comunidad cósmica que es al mismo tiempo ético, ideológico y existencial.

Esa comunidad se expresa con mayor propiedad por la palabra "nudo" (chinu en aymara, quipu en la lengua del runa), que grafica la idea de unión y de relación, más exactamente de interrelación ${ }^{17}$. Implica que todo está relacionado en el mundo en que vivimos, integrando un conjunto indiviso. En runasimi equivale a decir que todo está amarrado. $\mathrm{Al}$ anudar, en realidad se está amarrando. Anudar en quechua es sinónimo de atar. En runasimi se expresa esta acción mediante otro verbo, huatay, amarrar. Estar amarrado significa "estar con", pero también "poseer" o "estar poseído" por alguien o algo. Eliade ${ }^{18}$ lo recuerda a propósito de la pugna entre Vrtra e Indra, los dioses míticos, uno anudador y otro desanudador. Vrtra ata a las tinieblas, e Indra lo libera. El andino no arranca el ichu, por ejemplo, para anudar, antes bien, hace el nudo respetando la integridad de la planta; la gracia radica en que mientras anuda al mismo tiempo pronuncia un deseo, expresando con ello que el deseo queda amarrado al ichu. Estar amarrado es estar envuelto por un ligamento, laso o liwi y conectado a otro ser o a una fuerza natural o espiritual. Esa ligadura y la fuerza al que conecta pueden tener una valoración polarizada entre el bien y el mal, entre la vida y la muerte, o entre la luz y las tinieblas, siguiendo el contraste dialéctico de cosmos y caos. Un enfermo es alguien que está atrapado por una fuerza negativa que en quechua se conoce con el término katja. Al propio tiempo, katja es el humor maligno que exhala el cadáver, ya atrapado por la muerte, capaz de afectar a una persona viva.

Para el runa no existe esa distinción entre sujeto y objeto como ocurre en la mentalidad objetivante, pero tampoco se dan en un plano indiferenciado absoluto. La no-distinción no significa homogeneidad plena; al contrario, la idea de nudo convoca el concurso de sujetos y objetos que son distinguibles pero que están imbricados. La diferencia opera en el plano fenoménico y la no-distinción en el plano de lo esencial. El runa percibe la diferencia entre el ser sujeto y el ser cosa, y dependiendo de la naturaleza de cosa es posible reconocer el ser común entre sujeto y objeto. A esto se debe el principio de humanización de la naturaleza, por el cual la montaña, el río, el árbol, están animados de manera semejante que los animales y los hombres. El objeto, para el runa, no está distanciado, objetivado, extrañado, emancipado o aislado de él; el objeto para él es otro sujeto, el otro, con el cual mucho más que vivir enfrentado convive. En el reconocimiento del otro basa su ética y construyesu cosmovisión.

Parece existir un paralelo entre el pensamiento andino con el del Cusano en cuanto se refiere a la visión holística del cosmos y de cómo sus componentes están entramados. Solo que en el Cusano lo indiferenciado se manifiesta a través de entes naturales (desdoblados en sentimientos y experiencias: vivere y sentire) como una teofanía; mientras que en el andino opera el quinto elemento, el prin- 
cipio vital, Kamaqen, el que no es ajeno a la profusión de epifanías que acontecen en su entorno.

Tanto el enfoque holístico como la ideología basada en el "nudo cósmico" hacen inviable que el hombre de los Andes busque su origen e identidad fuera de la naturaleza. Kenko es una metáfora graficada por "lo torcido", o camino en zigzag, que lo lleva a encontrar su esencia al interior de la naturaleza, reduciendo su experiencia al "comienzo", a los ancestros, a los elementos naturales, en una suerte de búsqueda del tiempo perdido o viaje a la semilla.

\section{CONCLUSIÓN}

A diferencia del hombre occidentalizado, el andino se percibe como un ser integrado en una comunidad cósmica donde se cruzan los sentidos existenciales. Para la filosofía de occidente el ser humano ha seguido un proceso de diferenciación que lo ha desintegrado de la naturaleza, condición básica para definir no solo el tránsito de objeto a sujeto, sino de configurar su individualismo.

La búsqueda de la esencia del ser humano tanto en el occidental como en el andino van por caminos contrarios. En el occidental se dirige de la materia inorgánica al espíritu, en el andino la búsqueda de la esencia no procede de otro modo que viajando a la semilla, internándose en la propia naturaleza, en cuyos elementos pretende encontrar su origen, su identidad, su esencia.

\section{REFERENCIAS BIBLIOGRÁFICAS}

Bascopé, V. (2001). Percepción andina del mundo y ciclo de vida en Cochabamba. Revista Chungará V.33, $\mathrm{N}^{\circ} 2$.

Bertonio, L. (2006). Vocabulario de la lengua Aymara. Transcripción del
Texto Original de 1612. Arequipa, Perú: Ediciones El Lector.

Bouysse-Cassagne, T., Harris, O., Platt,

T. y Cereceda, V. (1987). Tres reflexiones sobre el pensamiento andino. La Paz, Bolivia: Hisbol.

Cassirer, E. (1968). Antropología filosófica. Introducción a una filosofía de la cultura (5ta. Edición). Mexico: Fondo de Cultura Económica. (1951). Individuo y cosmos en la Filosofía del Renacimiento. Buenos Aires, Argentina: Emecé editores, S.A.

Eliade, M. (1973). Mito y realidad (2da. Ed.). Madrid, España: Ediciones Guadarrama, S.A.

Estermann, J. (1997). Filosofía andina. Estudio intercultural de la sabiduría autóctona andina. Quito, Ecuador: Abya-Yala Editing.

Gonzalez Holguin, D. (1989). Vocabulario de la lengua general de todo el Perú Ilamada Lengua Qquichya o del Inca. Lima, Perú: Universidad Nacional Mayor de San Marcos, Edición facsimilar (1608).

Gordillo Begazo, J. (1996). Miculla, la magia de los signos. Tacna, Perú: EPF editores.

Grillo Fernández, E. y Rengifo, G. (1994). Crianza andina de la chacra. PRATEC, Proyecto andino de tecnologías campesinas. Lima.

Kessel, J. V. (1985). Medicina Andina; CIREN, Chile.

Kusch, R.(1971). El pensamiento indígenay popular en América. Edit. Instituto de Cultura Americana.

Levi-Strauss, C. (1970). Antropología Estructural. La Habana, Cuba: Instituto del libro.

- (1972)El pensamiento salvaje. Fondo de Cultura Económica.

Lira, J. A. (1944). Diccionario KechuwaEspañol. Argentina: Universidad Nacional de Tucumán. 
Manrique Enríquez, F. (2002). Pachasofia y runasofia andina. CONCYTEC, Colección Episteme. Lima.

Mejía Huamán, M. (1997). TEQSE. La cosmovisión andina y las categorías quechuas como fundamentos para una filosofía peruana y de América Andina. Lima, Perú: Universidad Ricardo Palma, Instituto de Cul- tura Andina.

Mondolfo, R.(1969). Breve historia del pensamiento antiguo. Buenos Aires, Argentina: Losada, Biblioteca Clásica y Contemporánea.

Morin, E. (1994). El método. El conocimiento del conocimiento. Cátedra.

Pease, F. (1973). El Dios Creador Andino. Mosca Azul, Edit.

'El pensamiento de Nicolás de Cusa tomados aquí están contenidos en la exposición de Ernst Cassirer en ef libro: Individuo y Cosmos en la filosofía del Renacimiento (Emecé Editores, S.A., Buenos Aires, 1951). Su nombre era Nicolaus Krebs o Chrypffs, pero fue conocido por Nicolás de Cusa por la ciudad en que nació, Kues. Hijo del naviero Johan Cryfts y de Catherina Roemer. Teólogo y filósofo, es considerado el padre de la filosofía alemana y, como personaje clave en la transición del pensamiento medieval al del renacimiento, uno de los primeros filósofos de la modernidad.

${ }^{2}$ Esta división trae a la memoria la imagen del mundo que brinda Platón: el mundo sensible, visible, de las apariencias; yel mundo inteligible, invisible, de las ideas.

El primer círculo compuesto de Serafines, Querubines y Tronos; el segundo circulo, de Dominaciones, Virtudes y Potestades; y el tercer círculo, de Principados, Arcángeles y Ángeles.

${ }^{4}$ Por analogia a la ruta propuesta por Bouelles, se planteaba la siguiente correspondencia: la tierra corresponde al primer orden, el agua al segundo; el aire al tercero y el fuego al cuarto orden, el más elevado, la imagen viva de la razón.

"Las ideas que siguen están expuestas en el libro: "El puesto del hombre en el cosmos", (Losada, S.A., Buenos Aires, 1938, Quinta Edición 1964; traducción de José Gaos; introducción de Francisco Romero), escrito por Scheler antes de 1928 , año en que fallece.

${ }^{6}$ Francisco Romero, en el estudio introductorio, define el Espiritu por su capacidad para "volverse hacia el mundo sui generis de los valores y de las ciencias" (p. 16)

' "Lo que el animal no tiene, seguramente-escribe Scheler-, es la facultad de preferir entre los valores mismos - por ejemplo, lo útil de lo agradable-prescindiendo de los bienes concretos y singulares. En todo lo afectivo, el animal está mucho más cerca del hombre que en lo que se refiere a la inteligencia. Ofrendas, reconciliaciones, amistades y otras cosas parecidas pueden encontrarse entre los animales" (p.54).

${ }^{8}$ Scheler ilustra el acto de ideación con el siguiente ejemplo. Si tomamos el dolor como un ejemplo práctico podríamos decir que es especifico a una parte del cuerpo, cuya explicación y solución correspondería a la ciencia positiva. Podría tratarse inclusive de un dolor psicológico sin dejar por ello de ser especifico. Pero si se orienta la pregunta al dolor mismo, ¿qué es?, prescindiendo de que ocurra aqui y ahora, la búsqueda de una respuesta posible se orienta hacia el fondo de las cosas para dar cuenta de lo que podria ser el dolor en general. M. Scheler afirma que la Ideación es la acción de comprender este dolor en general, que constituye una de las formas esenciales de la estructura del universo, prescindiendo del número de observaciones que hagamos y de las inferencias inductivas. Este tipo de conocimiento rebasa los limites de nuestra experiencia sensible y que es conocido en el lenguaje filosófico como a priori. 
Russell, B. (1974). Fundamentos de la Filosofía; Plaza \& Janes Editores.

Sartre, J. P. (2005). El ser y la nada. Ensayo de ontología fenomenológica. Buenos Aires, Argentina: Editorial Lozada S.A.

Scheler, M. (1964). El puesto del hombre en el cosmos (1938)(5ta Edición). Buenos Aires, Argentina: Editorial Losada, S.A.

Sobrevilla, D. (1987). ¿Pensamiento filosófico o pensamiento mítico precolombino? La cosmovisión Nahuatl y el surgimiento de la filosofía", en Búsqueda de la Filosofía en el Perú de Hoy. Cusco, Perú: Centro Bartolomé de las Casas.

Sowell, T. (1990). Conflicto de visiones: Orígenes ideológicos de las luchas políticas. Buenos Aires, Argentina: Gedisa Editorial.

\footnotetext{
'B. Russell: Fundamentos de la Filosofía; Plaza \& Janes Editores, 1974. Miembro del afamado Círculo de Viena

${ }^{10}$ Según el vitalismo, el espiritu sería un tardio "producto de la evolución" de la vida, sujeta a impulsos nutritivos, sexuales y reproductivos, o impulsos de poderio. Sin embargo, para Scheler, el vitalismo tiene el mérito de haber dado a conocer que "lo propiamente poderoso y creador en el hombre no es lo que llamamos el espiritu, ni las formas superiores de la conciencia, sino las oscuras, subconscientes, potencias impulsivas del alma" (Scheler, o.c.p, 111).

${ }^{11}$ El ritual del fuego, llevado a cabo en Miculla, el 20 y 21 de junio del 2012, fue organizado por el "movimiento de pueblos originarios", algunas de cuyas instituciones se encuentran en la ciudad de Tacna y vienen impulsando actividades tendientes a reivindicar el pensamiento, las creencias y los rituales ancestrales para poner de relieve la cultura originaria que, como la aymara, aglutina una activa participación de gente comprometida con esta cultura que se distribuye en cuatro naciones: Perú, Chile, Bolivia, Argentina. Sobre Miculla puede consultarse el estudio de Jesús Gordillo: Miculla, la magia de los signos, 1996. Igualmente su artículo sobre Moqui, publicado en la Revista La Vida \& la Historia Nro.1, 2013.

${ }^{12}$ Los siguientes son los pasos del ritual a la salida del sol: 1. Ingreso de los celebrantes al cuadrangulario, previa limpieza del cuerpo con licor de esencias, 2.Llegada del Yatiri mayor al centro del cuadrangulario (es el lider espiritual que dirigirá la ceremonia de ofrenda), 3.Ofrenda de incienso (participan todos), 4.Ofrenda de los "deseos", e invocación (de rodillas), 5.Salida por la avenida hacia la mudanza (con música), 6.Cremación de los "deseos" en el centro ceremonial, 7.Compartir (comida, bebida, música y danza).

${ }^{13}$ Eliseo Jaliri es un maestro aymara que ha alcanzado la categoria de abuelo, por su profundo conocimiento de su cultura y el dominio de sus ritos. (Grabado en el amanecer del 21 de junio del 2012 en Miculla).

${ }^{14}$ Según el diccionario aymara de Ludovico Bertonio (de 1609), kenko significa: "cosa tuerta que da buelta".

${ }^{15}$ Moqui pertenece a la comunidad de Cambaya, de la jurisdicción del distrito de llabaya (a tres horas en bus de la ciudad de Tacna); de llabaya a Cambaya hay una hora a través de una carretera afirmada, y de la localidad de Cambaya se escala en bus durante una media hora hasta un campamento próximo al escenario ceremonial, ya en el corazón de Moqui. Hay que caminar (a pie) un kilómetro para llegar al escenario elegido.

${ }^{16}$ Edgar Morin menciona el "holomorfismo" como uno de los principios del pensamiento complejo, según el cual el todo está contenido en las partes, y la parte expresa el todo. Este principio que sostuvo la base del pensamiento mágico, lo es en el pensamiento complejo.

${ }^{17}$ El quipu fue un instrumento de contabilidad entre los incas y una forma de memorización de su historia social, económica y cosmovisión. Véase Radicati Di Primeglio, Carlos "El sistema contable de los Incas. Yupana y Quipu". S/F, Librería Studium, Lima.

${ }^{18}$ En Mitoy Realidad; Anagrama, 1992.
} 